\title{
Secondary Malignant Neoplasm
}

National Cancer Institute

\section{Source}

National Cancer Institute. Secondary Malignant Neoplasm. NCI Thesaurus. Code C4968.

A malignant neoplasm that arises from a pre-existing lower grade lesion, or as a result of a primary lesion that has spread to secondary sites, or due to a complication of a cancer treatment. 